\title{
Quality Analysis of Indian Basmati Rice Grains using Top-Hat Transformation
}

\author{
Sheetal Mahajan \\ Research Scholar \\ Department of Computer \\ Science and Engineering \\ CTIEMT, Shahpur, Jalandhar
}

\author{
Sukhvir Kaur \\ Assistant Professor \\ Department of Computer \\ Science and Engineering \\ CTIEMT, Shahpur, Jalandhar
}

\begin{abstract}
Rice is one of the most important cereal grains. Rice is a good source of complex carbohydrates and is rich in several other essential nutrients. The paper presents a solution for quality analysis of Indian Basmati rice grains using Top-hat Transformation. In this paper the problem of Non-uniform Illumination for quality assessment is defined which show their effects in the process of extracting objects from the background and cause segmentation errors. The proposed method for quality assessment of Indian Basmati rice grains using Top-hat Transformation which achieves high degree of accuracy in correcting the effects of the Non-uniform Illumination than Computer Vision Inspection. The proposed method based on Morphological features is developed for counting the number of Indian Basmati rice grains with Normal grains, Long grains and Small grains.
\end{abstract}

\section{Keywords}

Top-hat Transformation, Quality, Morphological operations, Basmati rice grains, Parameters

\section{INTRODUCTION}

Rice is one of the most important cereal grains. Rice is one of the leading food crops of the world as more than half of the source of calories and proteins. The yield of rice is measured in million metric tons.

Basmati rice is a unique extra long slender grain variety of rice grown in India and Pakistan. They are famous for their light nutty flavor, delicate texture, delicious taste, delightful fragrance and softness. They remain separate and non-sticky after cooking. They have excellent aroma, sweet taste and post cooking elongation of more than twice its original length. The grain of Basmati rice has more length than width and they grow even longer as they cook. India is the largest cultivator and exporter of this rice and the majority of Basmati rice come from the fields of Punjab. The major export destinations are Iran, Saudi Arabia, Iraq, Kewait and United Arab Emirates. The areas of Basmati rice production in India are in the states of Jammu and Kashmir, Himachal Pradesh, Haryana, Uttrakhand, Punjab, Uttar Pradesh and Delhi.

Basmati rice is the most important grain with respect to human nutrition values and caloric intake. Basmati rice has no cholesterol and almost no fat and is rich source of carbohydrates. However, they also contain some amounts of Vitamins and Minerals. Since it is low in potassium and phosphorous content so those people with advanced Kidney disease can also benefit from eating Basmati rice.

The quality of rice is based on a variety of physical and chemical properties such as Head rice and Broken grains,
Long, Normal and Small grains. Foreign material like dirt, stones, Shape and Size of grains, Damage and Discolored grains, Color, Texture (how it feels when eaten), Aroma (how it smells), Moisture content, Chalkiness and Whiteness, etc. In agriculture industry, quality of grains is an important issue to protect the consumers from substandard products because the samples of the material are subjected to adulteration. The basic problem of rice industry for quality assessment is quality analysis of rice grains is done by visually and manually by Human Inspectors. Sometimes, the decisions taken by Human Inspectors may be affected by some external factors like Tiredness, Revenge, Fatigue, Eyesight, Work pressure, Climate, etc. Moreover, this evaluation process is however tedious, time-consuming and is neither objective nor efficient.

The researchers have worked to provide a solution to the problem of rice industry and thus provide Machine Vision based Inspection using Digital Image Processing for quality analysis of rice grains which is fast, accurate, convenient, harmless, non-destructive and cost-effective technique in comparison with traditional methods. But still there is a problem of Non-uniform Illumination i.e. dark areas and light areas in an image which show their effects in the process of extracting objects from the background and also cause segmentation errors due to an uneven illumination of the image. This paper presents a solution to this problem of rice industry by providing one method for quality analysis of Indian Basmati rice grains using Top-hat Transformation. An important use of Top-hat Transformation is in correcting the effects of Non-uniform Illumination. When we apply this Top-hat Transformation on the Gray scale image it provides uniform Illumination with no light and dark areas in an image that helps in the proper extraction of objects from the background. Thus, segmentation errors can also be removed.

\section{RELATED WORK}

Chetna V. Maheshwari, Kavindra R. Jain [1] provides Machine Vision quality analysis of rice grains to display the count for Normal, Long and Small rice seeds which achieves high degree of accuracy and quality as compared to Human Vision Inspection.

Harish S Gujjar, Dr. M. Siddappa [2] provides one method to test the purity of given samples of rice grains. It deals with the Pattern Classification technique based on Color, Morphological and Textural features for rejecting the Broken Basmati rice grains.

Bhavesh B. Prajapati, Sachin Patel [3] discusses the Digital Image Processing tool which measures the various parameters of rice samples and then compares the calculated parameters 
with existing standards as provided by Indian Government to classify the rice samples as Special, Grade A and Grade B samples.

Harpreet Kaur, Baljit Singh [4] provides one Machine algorithm to test the purity of rice grains, to analyse Head rice, Broken rice and Brewers and to classify the rice grains as Premium, Grade A, Grade B and Grade C.

Sanjivani Shantaiya, Uzma Ansari [8] provides one algorithm to identify the broken rice grains and Normal rice grains based on Color, Morphological and Textural features using training and testing by Neural Network technique.

Neelamegam P, Abirami. S, Vishnu Priya. K, Rubalya Valantina. S. [6] performed analysis on Basmati rice granules to evaluate the performance using Image Processing and Neural Network based on the features extracted from rice granules for classification grades of granules as Normal, Long and Small rice grains.

Bhupinder Verma [9] provides Watershed method for the grading of rice grains as Broken, Discolored, Damaged and Chalky grains. The calculated parameters are provided as input data to Neural Network for classification of rice grains.

Vinita Shah, Kavindra Jain, Chetna Maheshwari [5] presents a solution for quality evaluation and grading of Gujarat 17 rice using Image Processing and Soft Computing Technique. The proposed algorithm based on morphological features is developed for identification of unknown rice seed quality.

Liu Guang-rong [7] proposes one method to identify the color of rice grains based on Image Processing Technique and Color Models i.e. RGB color model and HIS color model.

Cheng Fang, Ying Yi-bin [10] proposes Machine Vision inspection of rice seeds based on Hough Transform. Hough transform is the projection of the image intensity along a radial line oriented at a specified angle. The proposed algorithm based on Hough Transform is developed for identification of Normal seeds, Fine Fissure seeds and unclosed seeds.

\section{METHODOLOGY}

Rice grains of two Indian Basmati varieties namely; 1121 Basmati Rice and Sharbati Basmati Rice were taken up for quality analysis task. The basic steps in the quality analysis of Indian Basmati rice grains using Top-hat Transformation are as follows:
a) Image Acquisition.
b) Convert RGB to Gray scale image.
c) Perform Morphological Closing and Opening operations.
d) Apply Top-hat Transformation on the image.
e) Image segmentation using Thresholding method.
f) Parameter calculation.
g) Histogram creation.
h) Compute Threshold values.
i) Display the count for Normal, Long and Small rice grains.

The block diagram for quality analysis of Indian Basmati rice grains using Top-hat Transformation is shown in Figure 1.
IMAGE ACQUISITION

CONVERSION RGB TO GRAY SCALE IMAGE

MORPHOLOGICAL OPEARTIONS

TOP-HAT TRANSFORMATION

IMAGE SEGMENTATION

PARAMETER CALCULATION

HISTOGRAM CREATION

COMPUTE THRESHOLD VALUES

RESULT OUTPUT

Fig 1: Block diagram for Quality Analysis of Indian Basmati Rice Using Top-hat Transformation

\subsection{Image Acquisition}

The first step in Image Processing is Image Acquisition. The images of Indian Basmati rice grains samples were acquired with a color Digital Camera of Nikon D3200 as shown in Figure 2 and Figure 3. The black background has been used. The acquired images are $4512 * 3000$ pixels in size i.e. 4512 pixels Width and 3000 pixels Height. Images are captured and stored in JPG format. Through data cable these images has been transferred and then stored in hard disk.

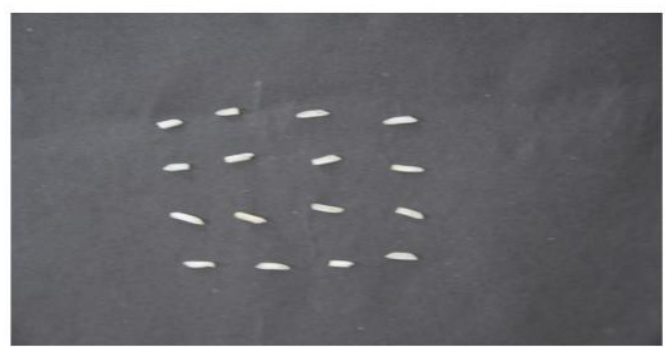

Fig 2: 1121 Basmati Rice

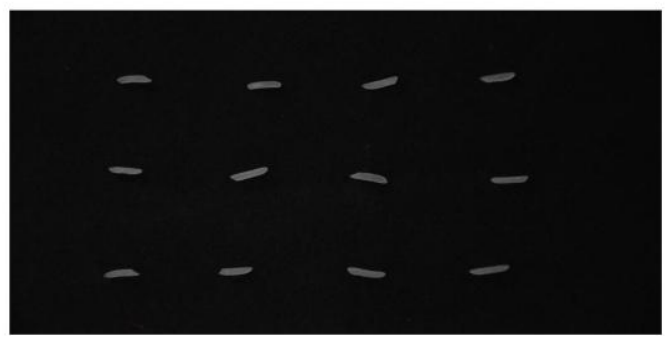

Fig 3: Sharbati Basmati Rice

\subsection{Convert RGB to Gray scale Image}

The acquired image is color image so we convert it into Gray scale as the color information is not of much importance. Use the rgb2gray function to convert the RGB image into a Gray 
scale image in both sample images as shown in Figure 4 and Figure 5 .

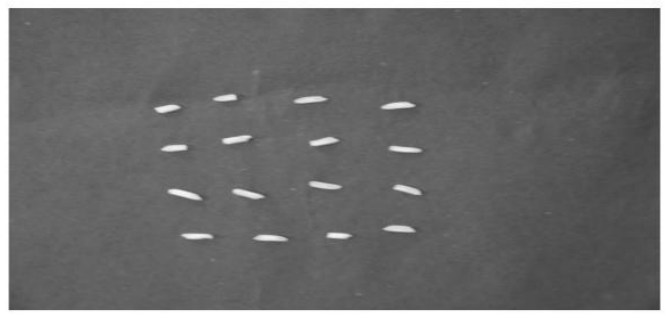

Fig 4: Conversion of 1121 Basmati Rice Image

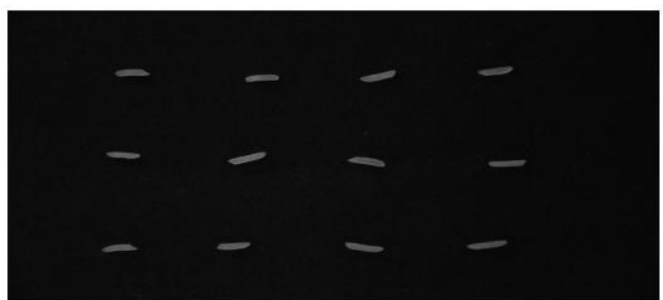

Fig 5: Conversion of Sharbati Basmati Rice Image

\subsection{Perform Morphological Closing Operation}

After image conversion from RGB to Gray scale, perform morphological closing operation on the Gray scale image on both sample images by using imclose function as shown in Figure 6 and Figure 7. Morphological closing operation tends to smooth the sections of the image. It also eliminates small holes from the image and fills gaps in the image.

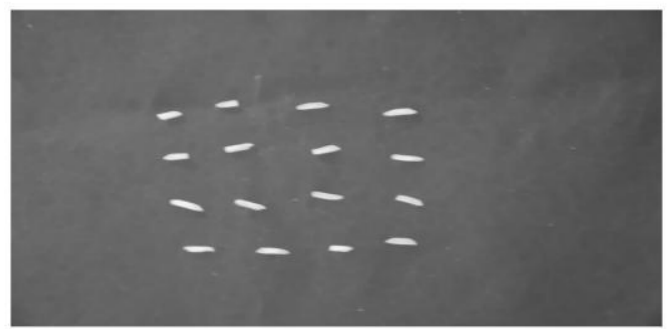

Fig 6: Morphological Closing Image of 1121 Basmati Rice

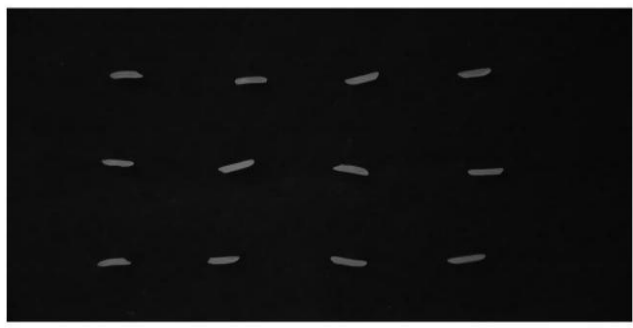

Fig 7: Morphological Closing Image of Sharbati Basmati Rice

\subsection{Morphological Opening Operation}

After morphological closing operation, perform morphological opening operation on the morphological closing image of both sample images by using imopen function as shown in Figure 8 and Figure 9. Morphological opening operation generally smoothes the objects of the image. Opening operation eliminates thin protrusions i.e. Remove noise. Opening operation has the effect of removing objects that cannot completely contain the structuring element.

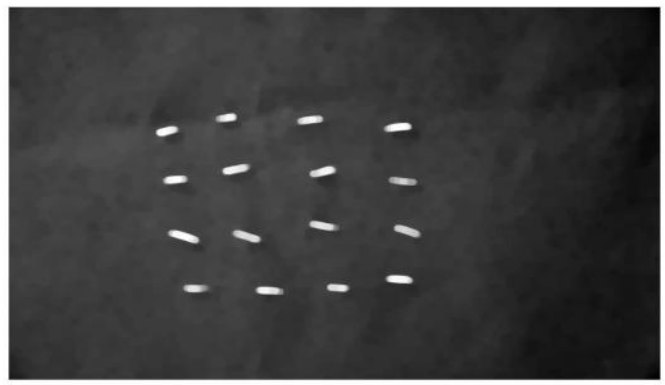

Fig 8: Morphological Opening Image of 1121 Basmati Rice

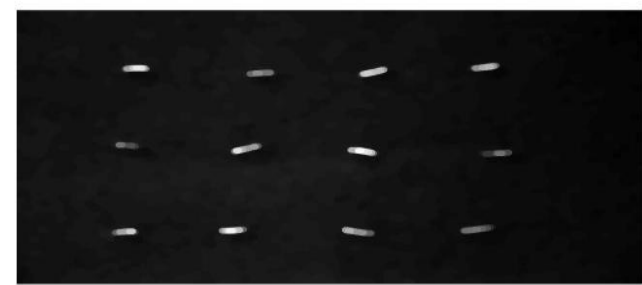

Fig 9: Morphological Opening Image of Sharbati Basmati Rice

\subsection{Apply Top-hat Transformation}

Top-hat Transformation is used for light objects on a dark background. Top-hat Transformation of a Gray scale image $f$ is defined as f minus its opening.

$$
\mathrm{T} \text { (hat) }(\mathrm{f})=\mathrm{f}-(\mathrm{fob})
$$

The principal application of this transformation is in removing objects from an image by using a structuring element in the opening or closing operation that does not fit the objects to be removed. An important use of Top-hat Transformation is in correcting the effects of Non-uniform Illumination. As we know that proper (Uniform) Illumination plays a central role in the process of extracting objects from the background. This process is called segmentation is one of the first steps performed in automated analysis.

Thus, after morphological opening operation, apply Top-hat Transformation on the morphological opening image of both sample images by using imtophat function as shown in Figure 10 and Figure 11. When we apply this Top-hat Transformation on the morphological opening image it provides Uniform illumination with no light and dark areas in an image that helps in the proper extraction of objects from the background. Thus, segmentation errors can also be removed.

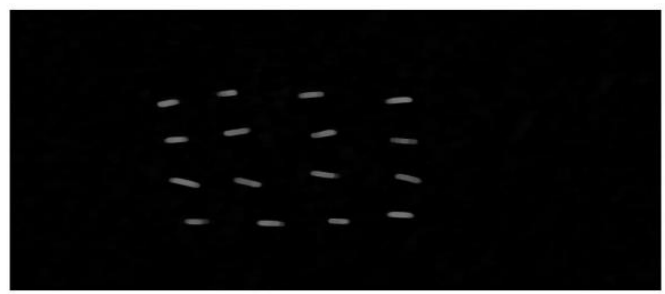

Fig 10: Top-hat Transformed Image of 1121 Basmati Rice 


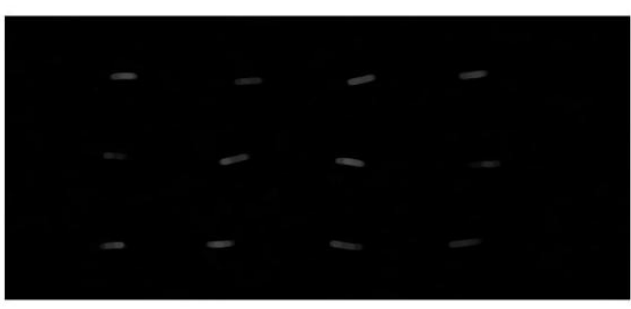

Fig 11: Top-hat Transformed Image of Sharbati Basmati Rice

\subsection{Image segmentation}

The image segmentation deals with the identification of objects with in an image. It deals with edge detection process i.e. identifies individual object boundaries and marks the centre of each object for further processing. Thresholding method is one of the fundamental approaches of segmentation. Thresholding method is used to locate objects and boundaries in images by using graythresh function also to convert the Gray scale image into Binary image of both sample images by using im 2 bw function as shown in Figure 12 and Figure 13.

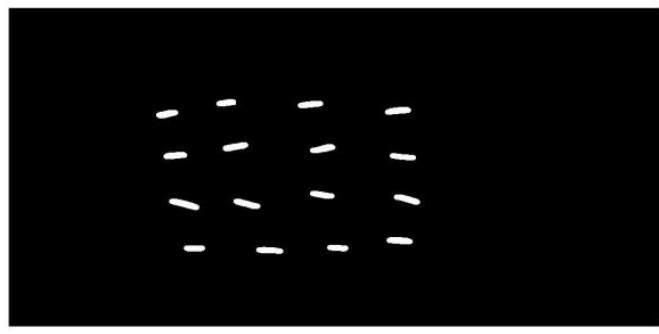

Fig 12: Segmented Image of 1121 Basmati Rice

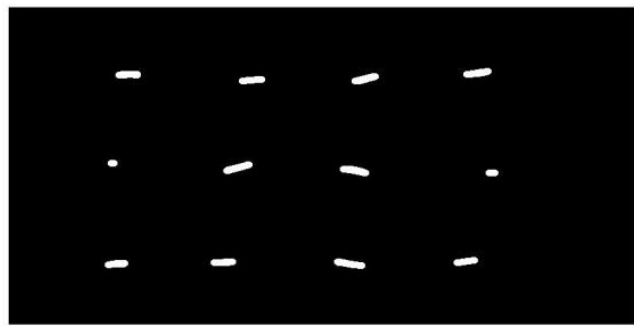

Fig 13: Segmented Image of Sharbati Basmati Rice

\subsection{Parameter Calculation}

The Matlab Version 10.0 is used for extracting features of Basmati rice grains. Extraction of quantitative information from segmented images is dealt with feature extraction. Here, we have extracted two parameters Major Axis Length and Minor Axis Length for differentiating Normal rice grain from Long grain as well as Small grain.

\subsubsection{Major Axis Length}

The major axis length of an image is defined as the length (in pixels) of the major axis of the ellipse that has the same normalized second central moments as the region.

\subsubsection{Minor Axis Length}

The minor axis length of an image is defined as the length (in pixels) of the minor axis of the ellipse that has the same normalized second central moments as the region.

\subsection{Histogram Creation}

The Histogram is a graph showing the number of pixels in an image at each different intensity value found in that image. Histogram diagrams for Major Axis Length and Minor Axis Length calculation computed from both the samples is shown in Figure 14-15 and Figure 16-17 from which we can clearly specify the range of major axis length and minor axis length for Small grains, Normal Grains and Long grains as well.

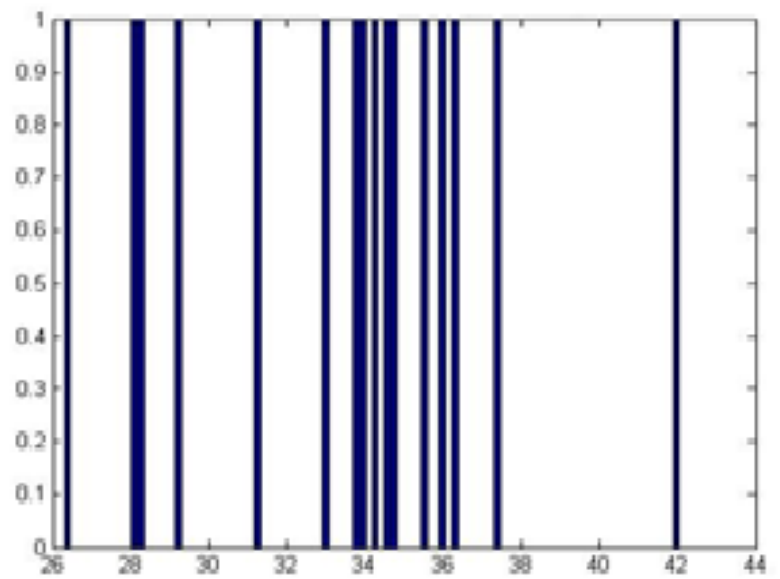

Fig 14: Histogram Showing Major Axis Length of 1121 Basmati Rice

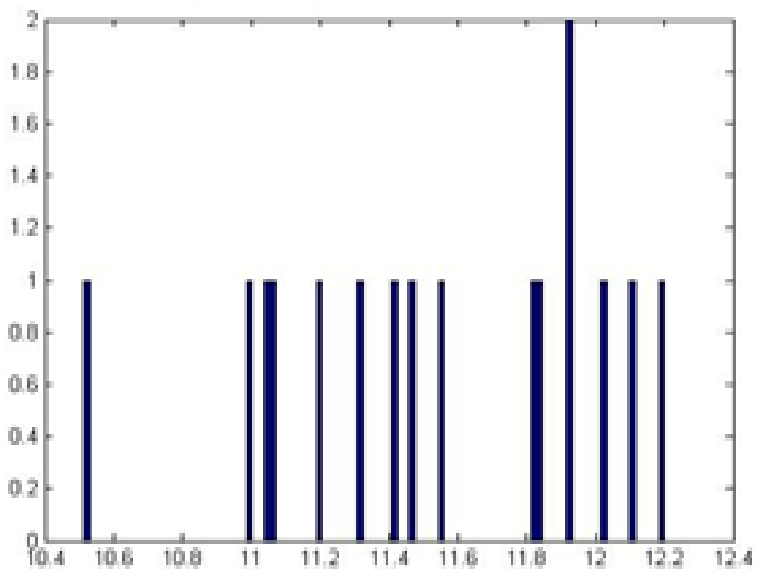

Fig 15: Histogram Showing Minor Axis Length of 1121 Basmati Rice

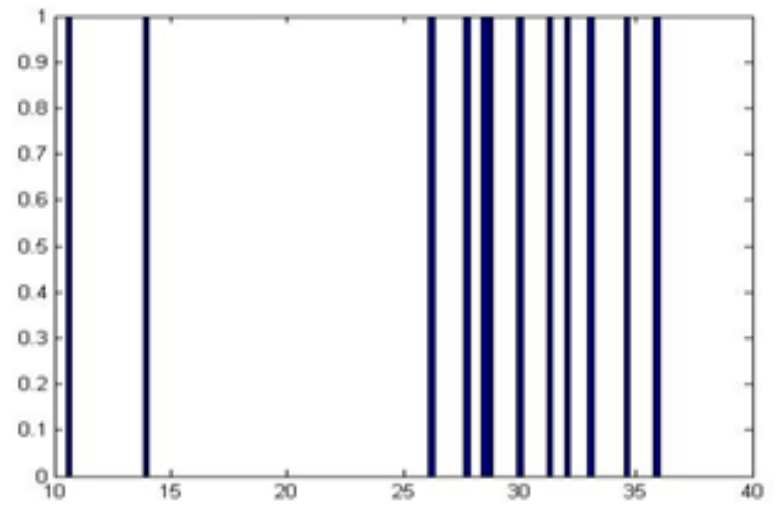

Fig 16: Histogram showing Major Axis Length of Sharbati Basmati Rice 


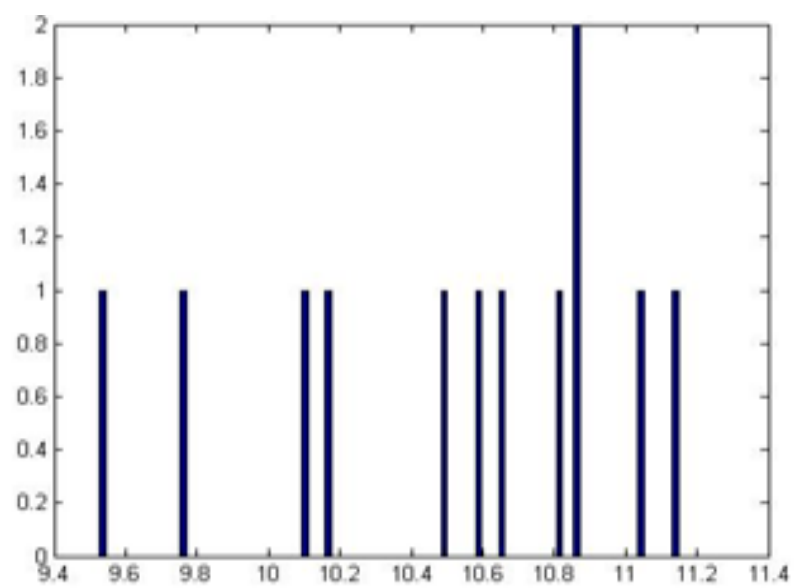

Fig 17: Histogram Showing Minor Axis Length of Sharbati Basmati Rice

\subsection{Compute Threshold Values}

For finding out the number of Normal rice grains, Long rice grains and Small rice grains, we compute threshold values using the histograms of Figure 14-15 and Figure 16-17 for parameters like Major Axis Length and Minor Axis Length as given in Table 1 and Table 2.

Table1. Computed Threshold Values for 1121 Basmati Rice

\begin{tabular}{|c|c|c|c|}
\hline $\begin{array}{c}\text { Quality } \\
\text { Measuring } \\
\text { Parameters }\end{array}$ & $\begin{array}{c}\text { Small } \\
\text { Grains }\end{array}$ & $\begin{array}{c}\text { Normal } \\
\text { Grains }\end{array}$ & $\begin{array}{c}\text { Long } \\
\text { Grains }\end{array}$ \\
\hline $\begin{array}{c}\text { Major Axis } \\
\text { Length }\end{array}$ & $26-30$ & $30-42$ & $42-44$ \\
\hline $\begin{array}{c}\text { Minor Axis } \\
\text { Length }\end{array}$ & $10.4-10.5$ & $10.5-11.9$ & $11.9-12.4$ \\
\hline
\end{tabular}

Table2. Computed Threshold Values for Sharbati Basmati Rice

\begin{tabular}{|c|c|c|c|}
\hline $\begin{array}{c}\text { Quality } \\
\text { Measuring } \\
\text { Parameters }\end{array}$ & $\begin{array}{c}\text { Small } \\
\text { Grains }\end{array}$ & $\begin{array}{c}\text { Normal } \\
\text { Grains }\end{array}$ & $\begin{array}{c}\text { Long } \\
\text { Grains }\end{array}$ \\
\hline $\begin{array}{c}\text { Major Axis } \\
\text { Length }\end{array}$ & $10-27$ & $27-35$ & $35-40$ \\
\hline $\begin{array}{c}\text { Minor Axis } \\
\text { Length }\end{array}$ & $9.4-10.1$ & $10.1-11.00$ & $11.00-11.4$ \\
\hline
\end{tabular}

\section{RESULTS AND DISCUSSIONS}

Quality analysis of Indian Basmati rice grains can be done based on assessment of parameters like Major Axis Length and Minor Axis Length. Table 3 and Table 4 show the calculated parameters values using Matlab 10.0 tool for each and every grain in the selected sample images.

Table3. Analysis for several seed available in 1121 Basmati Rice

\begin{tabular}{|c|c|c|}
\hline S.No & $\begin{array}{c}\text { Major Axis } \\
\text { Length }\end{array}$ & $\begin{array}{c}\text { Minor Axis } \\
\text { Length }\end{array}$ \\
\hline 1 & 29.15 & 12.20 \\
\hline 2 & 31.31 & 11.82 \\
\hline 3 & 42.04 & 11.84 \\
\hline 4 & 28.15 & 11.05 \\
\hline 5 & 26.29 & 11.54 \\
\hline 6 & 34.55 & 11.92 \\
\hline 7 & 37.35 & 11.46 \\
\hline 8 & 36.05 & 11.19 \\
\hline 9 & 33.70 & 11.31 \\
\hline 10 & 34.00 & 11.92 \\
\hline 11 & 32.93 & 11.06 \\
\hline 12 & 28.23 & 11.00 \\
\hline 13 & 34.67 & 12.02 \\
\hline 14 & 34.32 & 12.10 \\
\hline 15 & 35.51 & 10.51 \\
\hline 16 & 36.27 & 11.41 \\
\hline
\end{tabular}

Thus, by comparing the calculated parameter values with the threshold values, we can easily classify the rice grains as Normal, Long and Small rice grains. Table5 display the number of Normal, Long and Small rice grains in both sample images. Table 6 display the result of both samples as Normal, Long and Small grains based on Percentage value.

Table4. Analysis for several seed available in Sharbati Basmati Rice

\begin{tabular}{|c|c|c|}
\hline S. No & $\begin{array}{c}\text { Major axis } \\
\text { Length }\end{array}$ & $\begin{array}{c}\text { Minor Axis } \\
\text { Length }\end{array}$ \\
\hline 1 & 26.14 & 10.81 \\
\hline 2 & 10.50 & 9.52 \\
\hline 3 & 28.77 & 10.85 \\
\hline 4 & 28.40 & 10.48 \\
\hline 5 & 34.66 & 10.64 \\
\hline 6 & 29.96 & 10.16 \\
\hline 7 & 36.00 & 10.59 \\
\hline 8 & 33.19 & 11.14 \\
\hline 9 & 31.39 & 11.03 \\
\hline 10 & 27.84 & 10.10 \\
\hline 11 & 32.01 & 10.85 \\
\hline 12 & 13.84 & 9.75 \\
\hline
\end{tabular}


Table5. Result analysis of various samples based on Tophat Transformation

\begin{tabular}{|c|c|c|c|c|c|}
\hline $\begin{array}{l}\text { Sample } \\
\text { Name }\end{array}$ & $\begin{array}{c}\text { Quality } \\
\text { Measuring } \\
\text { Parameters }\end{array}$ & $\begin{array}{c}\text { Normal } \\
\text { Grains }\end{array}$ & $\begin{array}{c}\text { Small } \\
\text { Grains }\end{array}$ & $\begin{array}{c}\text { Long } \\
\text { Grains }\end{array}$ & $\begin{array}{c}\text { Total } \\
\text { Grains }\end{array}$ \\
\hline \multirow{2}{*}{$\begin{array}{c}1121 \\
\text { Basmati } \\
\text { Rice }\end{array}$} & $\begin{array}{l}\text { Major Axis } \\
\text { Length }\end{array}$ & 12 & 4 & 0 & 16 \\
\hline & $\begin{array}{l}\text { Minor Axis } \\
\text { Length }\end{array}$ & 13 & 0 & 3 & 16 \\
\hline \multirow{2}{*}{$\begin{array}{c}\text { Sharbati } \\
\text { Basmati } \\
\text { Rice }\end{array}$} & $\begin{array}{l}\text { Major Axis } \\
\text { Length }\end{array}$ & 7 & 4 & 1 & 12 \\
\hline & $\begin{array}{l}\text { Minor Axis } \\
\text { Length }\end{array}$ & 7 & 4 & 1 & 12 \\
\hline
\end{tabular}

Table6. Result analysis of various samples based on Percentage value

\begin{tabular}{|c|c|c|c|c|c|}
\hline $\begin{array}{l}\text { Sample } \\
\text { Name }\end{array}$ & $\begin{array}{c}\text { Quality } \\
\text { Measuring } \\
\text { Parameters }\end{array}$ & $\begin{array}{c}\text { Normal } \\
\text { Grains\% }\end{array}$ & $\begin{array}{c}\text { Small } \\
\text { Grains\% }\end{array}$ & $\begin{array}{c}\text { Long } \\
\text { Grains\% }\end{array}$ & $\begin{array}{c}\text { Total } \\
\text { Grains }\end{array}$ \\
\hline \multirow{2}{*}{$\begin{array}{c}1121 \\
\text { Basmati } \\
\text { Rice }\end{array}$} & $\begin{array}{c}\text { Major Axis } \\
\text { Length }\end{array}$ & 75 & 25 & 0 & 16 \\
\hline & $\begin{array}{c}\text { Minor Axis } \\
\text { Length }\end{array}$ & 81 & 0 & 18 & 16 \\
\hline \multirow{2}{*}{$\begin{array}{c}\text { Sharbati } \\
\text { Basmati } \\
\text { Rice }\end{array}$} & $\begin{array}{c}\text { Major Axis } \\
\text { Length }\end{array}$ & 58 & 33 & 8 & 12 \\
\hline & $\begin{array}{l}\text { Minor Axis } \\
\text { Length }\end{array}$ & 58 & 33 & 8 & 12 \\
\hline
\end{tabular}

Figure 18 and Figure 19 display graphical representation for the number of Normal, Long and Small rice grains in both sample images.

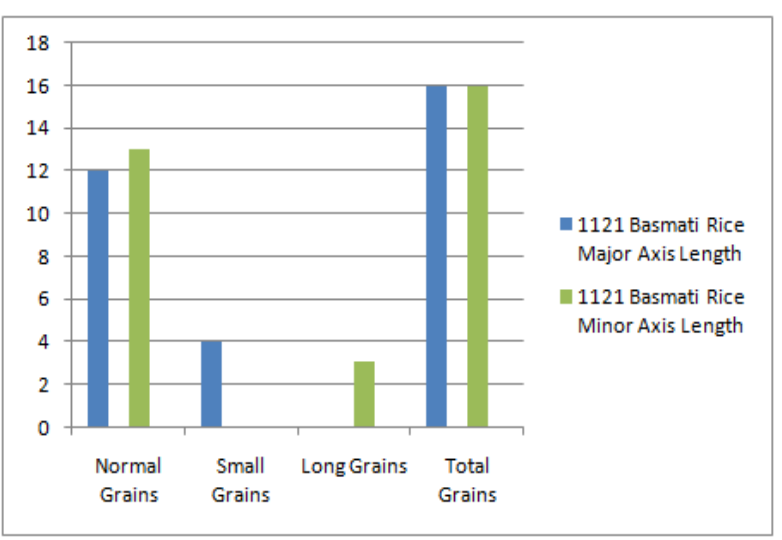

Fig 18: Graphical Result Analysis of 1121 Basmati Rice using Top-hat Transformation

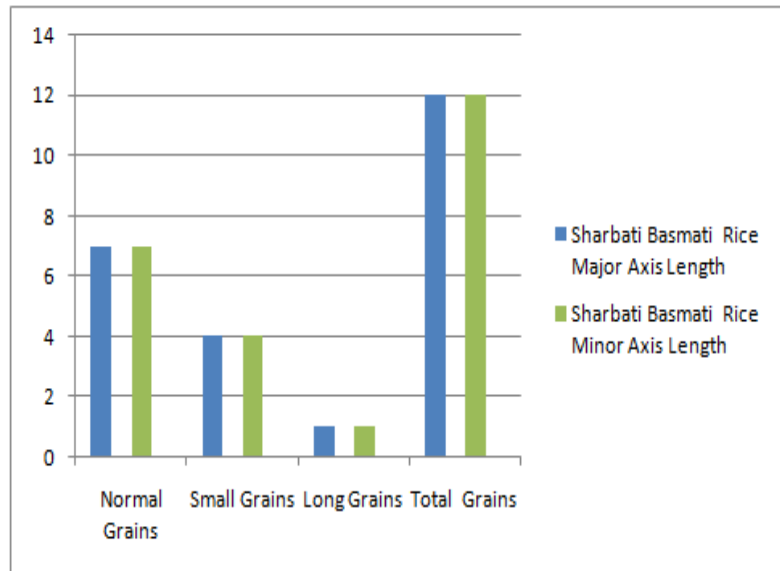

Fig 19: Graphical Result Analysis of Sharbati Basmati Rice using Top-hat Transformation

\section{CONCLUSION AND FUTURE WORK}

This paper presents the new method to solve the problem of Non-Uniform Illumination of the image using Top-Hat Transformation. This method is fast, accurate, convenient, harmless, non-destructive and cost-effective. It can achieve high degree of quality. It can classify the rice grains with greater speed and accuracy. We have calculated Major Axis Length and Minor Axis Length for counting Normal grains, Long grains and Small grains. Rice grains with more number of Normal grains are considered to be of good quality. As Long and Small grains are considered as foreign elements. Since, the 1121 Basmati rice has more number of Normal grains than Sharbati Basmati rice grains. Thus, 1121 Basmati rice grains are considered to be of good quality than Sharbati Basmati rice grains.

For quality analysis, the work can be done with more number of parameters and by using some other techniques and methods for more effective and efficient results.

\section{ACKNOWLEDGMENTS}

The making of the paper needed co-operation and guidance of all members of the department. I therefore feel privileged to thank all those who helped to make it successful. It is my immense pleasure to express my Gratitude to Sukhvir Kaur (Assistant Professor of Computer Science Department) as a guide who provided constructive and positive feedback during the preparation of the paper.

\section{REFERENCES}

[1] Chetna V. Maheshwari, Kavindra R. Jain, "Parametric quality analysis of Indian Ponia Oryza Sativa SSP Indica (rice)", in International Journal for Scientific Research and Development (IJSRD), ISSN: 2321-0613, Volume 1, Issue 2, pp. 112-116, 2013.

[2] Harish S Gujjar, M. Siddappa, "A method for Identification of Basmati rice grain of India and its quality Using Pattern Classification”, in International Journal of Engineering Research and Applications (IJERA), ISSN: 2248-9622, Volume 3, Issue 1, pp. 268 273, January-February 2013.

[3] Bhavesh B. Prajapati, Sachin Patel, "Classification of Indian Basmati rice using Digital Image Processing as per Indian export rules", in International Research Journal of Computer Science Engineering and Applications (IRJCSEA), ISSN: 2319-8672, Volume 2, Issue 1, pp. 234-237, January 2013. 
[4] Harpreet Kaur, Baljit Singh, "Classification and grading rice using Multi-Class SVM", in International Journal of Scientific and Research Publications (IJSRP), ISSN: 2250-3153, Volume 3, Issue 4, pp. 1-5, April 2013.

[5] Vinita shah, Kavindra Jain, Chetna Maheshwari, "Nondestructive quality analysis of Gujarat 17 Oryza Sativa SSP Indica (Indian rice) using Artificial Neural Network", in International Journal for Scientific Research and Development (IJSRD), ISSN: 2321-0613, Volume 1, Issue 3, pp. 697-700, 2013.

[6] Neelamegam. P, Abirami. S, Vishnu Priya. K, Rubalya Valantina. S. , "Analysis of rice granules using Image Processing and Neural Network", in IEEE Conference on Information and Communication Technologies (IEEE), ISBN No. 978-1-4673-5758-6, pp. 879-884, 2013.
[7] Liu Guang-rong, "Rice color inspection based on Image Processing Technique", in International Conference on Advances in Energy Engineering (IEEE), ISBN No. 9781-4244-7830-9, pp. 134-137, 2010.

[8] Sanjivani Shantaiya, Uzma Ansari, "Identification of food grains and its quality using Pattern Classification", in IJCCT, Volume 2, Issue 2,3,4, 2010

[9] Bhupinder Verma, "Image Processing Techniques for Grading and Classification of rice", in International Conference on Computer and Communication Technology (IEEE), ISBN No. 978-1-4244-9033-2, pp. 220-223, 2010

[10] Cheng Fang, Ying Yi-bin, "Machine vision inspection of rice seeds based on Hough transform", in Journal of Zhejiang University Science, ISSN: 1009-3095, pp. 663667, 2004. 